\title{
Radiation Therapy Treatment Planning and Simulation
}

National Cancer Institute

\section{Source}

National Cancer Institute. Radiation Therapy Treatment Planning and Simulation. NCI

Thesaurus. Code C116434.

The creation of a strategy, and the rehearsal of that strategy, for the purpose of identifying and eliminating any problems that may present during treatment. 